derivaría Adam Smith del sentimiento de la "simpatfa» y de la aparición del "espectador imparcial». Sólo comprende unas pocas reglas éticas o sistémicas fundamentales, a saber:

- «la estabilidad de la posesión»;

- «su transferencia por consentimienton; $y$

- "el cumplimiento de las promesas".

Nos encontramos, pues, con dos resultados sorprendentes al criticar la "paradoja del capitalismo". Uno es que la base moral del capitalismo no es el egofsmo, el vicio y la corrupción, como dicen tantos amigos de la sociedad cerrada y tribal. El peligro no viene del efecto sobre la sociedad de la corrupción de las costumbres morales.

Otro es que, además de contribuir le doux commerce, en expresión de Montesquieu, a la difusión de las costumbres civilizadas, nacidas del amor propio y la «simpatía», da lugar a que aparezca una meta-moral, una ética, un conjunto de reglas sistémicas que no son en sí ni morales ni inmorales, sino que han servido a lo largo de los años para arropar el crecimiento de la riqueza en un ambiente de seguridad. La ética del sistema capitalista está constituida por muy pocas reglas de justicia formal, no necesariamente acordes con los sentimientos morales prevalentes en la mayoria de una sociedad determinada.

Es decir, que es cierto que puede haber un conflicto entre los sentimientos morales de gran parte de la población de una sociedad capitalista, y las reglas éticas (o de la justicia) de respeto de la propiedad privada, la libertad de contratos, de respeto de los precios libremente formados, y del cumplimiento de los contratos, por el carácter abstracto y agnóstico de éstas.

Pero el comentario sobre las dificultades del hombre moderno de aceptar como justas valoraciones que no son ni naturales ni racionales, sino que son nacidas de la evolución social, debe ser objeto de otro trabajo.

\title{
El «éxito» del neoliberalismo
}

\author{
ANTONIO GARCIA SANTESMASES \\ U.N.E.D.
}

Creo que la forma más acertada de estudiar las distintas caras del neoliberalismo es plantear la relación entre democracia y capitalismo en cste fin de siglo. La relación entre democracia y capitalismo ha pasado por distintas etapas, pero conviene recordar que a principios de siglo la tesis que prevalecía en el campo liberal y en el mundo socialista era la de la incompatibilidad entre democracia y capitalismo. Para los liberales el temor fundamental se cifraba en los peligros que a su juicio entrañaría la extensión del sufragio universal. Para los socialistas, por el contrario, la gran esperanza se cifraba en la extensión del sufragio, ya que si votaban todos, siendo los más los asalariados, éstos podrian articular una coalición invencible frente a los menos 
que ostentaban la propiedad de los medios de producción. Para unos la maligna combinación entre liberalismo y democracia provocaría consecuencias indeseables por un falso sentido del igualitarismo que irfa en perjuicio de las elites que deben regir toda sociedad, la democracia acabaría siendo «morbosa». Para los socialistas, por el contrario, sólo gracias a esa extensión del sufragio era posible alcanzar por el camino de la legalidad el tránsito a otra sociedad y conseguir que el socialismo fuera el auténtico heredero del liberalismo.

Estas posiciones que centraban el debate a comienzos de siglo fueron puestas en cuestión de una forma dramática por la primera guerra mundial. Tras la carnicería humana terminaba toda una época, a partir de entonces liberalismo y socialismo serán combatidos por el fascismo y el leninismo.

El fascismo atacando duramente las "caducas instituciones democrático-liberales» y el leninismo oponiendo la democracia de los trabajadores, dirceta y auténtica, a la democracia de los parlamentos, estrecha y mezquina, combatirán cualquier posibilidad de acuerdo.

El acuerdo no llega, y es algo que se olvida hoy con excesiva frecuencia, hasta que no concluye la segunda guerra mundial. Es verdad que las experiencias de Estados Unidos y de Suecia son excepciones a esta regla pero es indudable que en Europa occidental solo con el final del conflicto bélico se produce un reconocimiento de las instituciones democratico-representativas $y$ un esfuerzo por evitar las causas que habran conducido a la crisis de los años treinta. Todo el debate de los años sesenta acerca del "fin de las ideologlas» no se puede entender si no es a partir de esta constatación de la necesidad del pacto, del acuerdo, de la con- certacion. Es importante por ello recordar que aquellos que van a aparecer como precursores de los neoliberales actuales son vistos en aquellos tiempos como personajes exúticos. Un liberal tan importante como R. Aron llegará a decir: "La crítica que llamaremos "liberal-individualista" de la cual el libro de F.A. Hayek constituye la expresión más sistemática y más elocuente no tiene ningún exito fuera de ciertos circulos restringidos. Temo incluso que la mayor parte de mis lectores se sorprendan de la importancia que le atribuyo al colocarla en el mismo plano que la crítica procedente del otro bando. Lo hago intencionadamente porque los no conformistas merecen simpatía y estima. Pues bien, F.A. Hayek es un no conformista por excelencia, un no conformista que al defender la causa del individualismo liberal va a contracorriente y sabe que ha elegido la soledad s.' Aron pensaba que las ideas de Hayek no habían sido seriamente estudiadas ya que aun aceptando que "la economfa mixta, la democracia liberal y el Welfare State parezcan ser actualmente el mejor compromiso entre las diversas libertades que la sociedad moderna ambiciona dar a los hombres, existen objeciones venidas de aquellos que querfan limitar los poderes del Estado y lo arbitrario de la administración, con el fin de dejar a la iniciativa individual y a la esfera privada el más amplio campo posible».2

Esas objeciones existian pero no eran las objeciones a las que Aron daba mayor importancia. Para él, como para otros muchos liberales, liberalismo era oponerse al sistema de partido único y al totalitarismo $y$ en este sentido habra un amplio margen de coincidencias entre la izquierda moderada y el liberalismo. Sus escritos en este punto son inequivocos: «El marxista-leninista afirma, o mejor di- 
cho decreta una verdad universal, negándose a distinguir entre lo que sabe y lo que quiere, el liberal o el pensador crítico, consciente de las celadas que le tienden sus pasiones, consciente del equívoco de la realidad misma, cuestiona constantemente sus hipotesis y sus juicios. ¿Escepticismo? En absoluto. El liberal busca pacientemente la verdad, jamás se apartara de sus convicciones altimas, es decir, de sus máximas tanto morales como intelectuales. Yo no me equivocaba al oponer $\mathrm{mi}$ actitud a la de los verdaderos creyentes, a la de los fieles, a las religiones seculares. Si me equivocaba al llamar a la una ideológica y a la otra no ideológica. Más vale recobrar, modificándolo un título de Pascal: Del buen uso de las ideologías". ${ }^{3}$

Este liberalismo que tenía muy clara su oposición al marxismo-leninismo opinaba que era falso que la intervención del Estado en la economía condujera inexorablemente a la planificación total y ésta al Estado totalitario y abogaba por un "Estado que puede y debe garantizar a todos, por medio de leyes sociales, un mínimo de recursos que haga posible una vida decente, al nivel que tolera la riqueza colectiva. El Estado deberia esforzarse por reducir los beneficios $\sin$ justificacion, aunque fuese suprimiendo ciertas formas de propiedad. Tiene derecho a percibir de los privilegiados una contribución a los gastos públicos que crezcan con el nivel de las rentas. Puede y debe amortiguar los fracasos o la debilitación relativa de los grupos, los individuos o las regiones desgraciadas en la carrera del progreson. ${ }^{4}$

Cualquiera que escuche los discursos que se pronuncian en nuestro pais acerca del subsidio de paro, del plan de empleo rural, de la presión fiscal se dará cucnta de la distancia entre uno y otro momento, entre las distintas caras del liberalismo. Para captar las diferencias entre los discursos ideológicos que dieron vida al Estado del bienestar y el neoliberalismo nada mejor que las afirmaciones de David A. Stockman: "La Revolución Reagan, tal como yo la había definido, exigía un asalto frontal contra el Estado-providencia norteamericano [...] por consiguiente cuarenta años de promesas, subvenciones, derechos adquiridos, todo ello concedido por el gobierno federal a incontables estamentos y estratos de la sociedad norteamericana, tendría que desaparecer o sufrir drásticas modificaciones. Una verdadera revolución en la política económica implicaba una batalla a muerte con todos los cuerpos electorales destinatarios de la generosidad de Washington [...] $3 .^{5}$ No es ahora el momento de enjuiciar si los propósitos reaganianos triunfaron o si fueron olvidados ante el "triunfo de la políticas, lo que importa ahora es retener la idea central que subyacía a todo el proyecto: "[...] esa idea central no era otra sino la del gobierno minimalista, entidad enjuta y tacaña, que repartiria justicia pública con ecuanimidad y nada más. La visión de la buena sociedad descansaba en el vigor y la capacidad productiva de los hombres libres en unos mercados libres. Trataba de fomentar la expansión sin trabas de la riqueza capitalista y el crecimiento del bienestar social que deriva automáticamente de aquella".

Aqui es donde están las grandes diferencias entre la obra de Hayek y el neoliberalismo posterior, Cuando $\mathrm{Ha}$ yek escribía en 1943 sacialismo, como él mismo se encarga de recordar en el prefacio de 1976 a Camino de sevidumbre, significaba «la nacionalización de los medios de producción y la planificación económica centralizadas, mientras que en los sesenta y los setenta ssocialismo ha llegado a signifi- 
car fundamentalmente una profunda redistribución de las rentas a través de los impuestos y de las instituciones del Estado benéficon.?

El gran éxito del neoliberalismo ha sido desplazar el debate hacia la derecha, hacia los distintos tipos de capitalismo. El gran acuerdo entre las fuerzas del capital y las organizaciones representativas del movimiento obrero pasaba por un respeto a la acumulación privada y una posibilidad de pro. ducir una legitimación pública a través de las instituciones del Estado de bienestar. Se entendía que sin pleno empleo, sin igualdad de oportunidades, sin seguridad social, no era posible conseguir la integración de los sectores populares en las instituciones democrático-representativas. La experiencia de los años treinta estaba cerca y se recordaba la dificultad de conciliar legitimidad política con una situación de paro, de pobreza, de marginación social. La izquierda europea había renunciado a un programa anticapitalista, a un socialismo que postulara la propiedad colectiva de los medios de producción y la planificación económica y se contentaba con la redistribución de la renta y las instituciones del Estado del bienestar. En el modelo europeo, con diferencias entre laborismo británico, socialdemocracia alemana y socialdemocracia sueca, lo csencial era la política de pleno empleo y el poder sindical. Es cierto que esa política de compatibilizar crecimiento económico y equidad se realizaba con una reducción del debate político a reivindicaciones economicistas acerca de los porcentajes a repartir en las partidas presupuestarias y dejaba a un lado todas las perspectivas posteconomicistas que reivindicaria la nueva izquierda $y$ los nuevos movimientos sociales. El exito del neoliberalismo es que al haber desplazado el debate de una forma tan manifiesta hacia la derecha, hacia la percepción de que sỏlo es posible elegir entre distintos tipos de capitalismo, ha provocado el olvido de toda crítica de izquierda al Estado de bienestar.

$Y$, sin embargo, esa crítica se habla producido y había sido muy consistente en la denuncia de la reducción economicista del debate político y contra el carácter eurocéntrico de las conquistas alcanzadas. La reivindicación libertaria de una democracia dentro del Estado social y la petición de una extensión de la solidaridad internacional fueron perdiendo relevancia ante la fuerza de la revolución conservadora.

Como ha señalado $H$. Young: "Los tories llegaron decididos a revertir las principales premisas de la política de posguerra, que eran cuatro. En primer lugar, se suponía que la mezcla del sector público y del sector privado que siguió al gobiemo de Atlee era más o menos acertada, segundo que la persecución de la plena ocupación era la tarea central de la dirección económica. Tercero que la redistribución hacia la igualdad de la riqueza era más importante que comenzar por generar rique$z a$, cuarto que los sindicatos eran la expresión de un saludable equilibrio social que servia bien al país», ${ }^{8}$ Frente a estas premisas los conceptos rectores de $M$. Thatcher eran otros: "Imaginaba un Estado más pequeño, una economía más orientada hacia el mercado, una ciudadanía obligada a aceptar sus propias decisiones. Deseaba sindicatos más débiles y empresarios más fuertes, el debilitamiento de los recaudos colectivos y mejores oportunidades para la autoayuda individual. Consiguió infundir a todas estas formulas un enérgico propósito moral, que demostraba que en cierto sentido absoluto ella tcnía razón y que con la misma certidumbre los socialistas estaban equivo- 
cados. En general estaba decidida a borrar el socialismo de la agenda británica. Según dijo cierta vez después del cuarto periodo nada quedaria del socialismon."

No se puede ignorar ni infravalorar la fuerza del mensaje thatcheriano. Los cuatro pivotes de la posguerra: la economía mixta, el pleno cmpleo, el poder sindical, el papel redistribuidor del Estado han sido radicalmente puestos en cuestión. Tras el ainvierno del descontenton todo el esfuerzo de M. Thatcher fue demostrar a la opinión pública que en Inglaterra el poder estaba en manos del gobierno y no de los sindicatos. La pregunta, decisiva para auscultar las causas de la erosión de las bases de apoyo al Estado del bienestar, es como se fue produciendo esa pérdida de apoyo a principios que habian sido fundamentales en la política de la posguerra. Entre las diversas explicaciones sobresale por su importancia la aplicación del modelo de la sociedad de los dos tercios a lo que estaba ocurriendo. La división de la sociedad en un tercio dominante, un segundo tercio compuesto por profesionales, tecnicos, funcionarios, clase obrera organizada y un tercer tercio abocado a la marginación, a los trabajos precarios, a la flexibilidad, a la inseguridad. La capacidad del «capitalismo popular" estriba on incorporar a sectores de la clase obrera al segundo tercio y fragmentar decisivamente el mercado laboral entre unos trabajadores con empleo fijo, seguridad social, acceso al consumo y otros sin identidad, sin poder construir su futuro, sin tener un horizonte de vida mínimamente estable. El recoger algunos de los bencficios del sisterna y el quedar abandonados a la propia suerte fue uno de los mecanismos más importantes para dividir a los sectores populares. Esta división tuvo una consecuen- cia electoral que Galbraith ha señalado con acierto: "En el pasado, los afortunados económica y socialmente eran, como sabemos, una pequeña minoria, un pequeño grupúsculo que dominaba y gobernaba. Hoy representan una mayoría aunque, como ya se ha dicho, una mayoría no de todos los ciudadanos sino de los que realmente votan. Es preciso y oportuno hacer mención a los que se hallan en esa situación y que responden en las urnas. Les llamaremos la mayoría satisfecha, la mayoria electoral satisfecha 0 , en una vísión más amplia, la cultura de la satisfacción. Hay que insistir, porque es ast, en que esto no significa que sean una mayoría de todos los que tienen derecho a votar. Gobiernan bajo el cómodo abrigo de la democracia, una democracia en la que no participan los menos afortunados". ${ }^{10}$ Galbraith hace un análisis de los componentes de esta "mayoría electoral satisfecha" pero lo que interesa resaltar aquí es el cambio en la mentalidad que es esencial para entender el "éxito" del neoliberalismo. Ese cambio de mentalidad Galbraith la sitúa en tres elementos: "La primera característica y la más generalizada de la mayoría satisfecha es su afirmación de que los que la componen están recibiendo lo que se merecen en justicia. Lo que sus miembros individuales aspiran a tener y disfrutar es el producto de su inteligencia, de su esfuerzo y de su virtud personales. La buena fortuna se gana o es recompensa al mérito $y$, en consecuencia, la equidad no justifica ninguna actuación que la menoscabe o que reduzca lo que se disfruta o podría disfrutarse" " La segunda característica de la mayoría satisfecha [...] es su actitud hacia el tiempo. Sintetizando al maximo siempre prefieren la no actuación gubernamental, aún a riesgo de que las consecuencias pudieran ser alarmantes a largo plazo. La 
razón es bastante evidente. El largo plazo puede no llegar, esa es la comoda y frecuente creencia. $Y$ una razón más decisiva e importante: uel coste de la actuación de hoy recae o podria recaer sobre la comunidad privilegiada, podrían subir los impuestos. Los beneficios a largo plazo muy bien pueden ser para que los disfruten otros. En cualquier caso la tranquila teología del latsser faire sostiene que, al final, todo saldra bien ${ }^{12}$ La tercera característica remite al papel del Estado: «Una tercera característica de quienes disfrutan de una posición desahogada es su vision sumamente selectiva del papel del Estado. Hablando vulgar y superficial. mente el Estado es visto como una carga, ninguna declaración política de los tiempos modernos ha sido tan frecuentemente reiterada ni tan ardorosamente aplaudida como la necesidad de quitar el "Estado de las espaldas de la gente". La necesidad de aligerar o eliminar carga tan agobiante y con ello, agradablemente los impuestos correspondientes es artículo de fe absoluto para la mayoria satisfechas..$^{13}$

Cuando hablamos del éxito del ncoliberalismo no es porque pensemos que el precio de estas políticas no haya sido tremendo ni porque desconozcamos los focos de protesta y de resistencia que han provocado, pero es cierto que esa devaluación de lo público, ese elogio del mercado, esa defensa del individualismo posesivo ha ido penetrando en la cultura política europea de una forma apabullante. Recordemos en este punto lo que han repetido a lo largo de estos años, como voz que clama en el desierto, los que han combatido más duramente esta filosofía neoliberal. Me refiero a los dirigentes sindicales: "A la posición de abandono de la izquierda se ha correspondido un avance devastador de la derecha neoliberal que ha significado un fuerte de- terioro de lo social, de las conquistas del Estado del bienestar y de las propias relaciones laborales. Buena parte de los partidos socialistas en el poder han abandonado todo afán transformador o reformista, característico de la izquierda, perdiendo con ello su más genuina seña de identidad. Como hemos afirmado en otras ocasiones, esos partidos llamados socialistas han perdido su alma y, en el mejor de los casos, se han hecho meros gestores de un capitalismo que cada vez les arranca más concesiones pragmáticas, hasta terminar haciéndoles cómplices $\mathrm{e}$ incluso abanderados de sus contrarreformas [...] la izquierda europea no ha querido ( $y$ en todo caso no ha podido) ofrecer una alternativa al discurso neoliberal".14 Cuando N. Redondo (autor de las anteriores palabras) tenga que ejemplificar en qué puntos no observa una alternativa al neoliberalismo, curiosamente vuelven a aparecer los puntos que eran centrales en el thatcherismo. Para la "dama de hierro" era esencial combatir la economía mixta, el pleno empleo, el poder sindical y el papel redistribuidor del Estado. Para Redondo la política desarrollada por la izquierda en el gobierno ha adoptado plenamente el discurso neoliberal: « $\mathrm{Ha}$ defendido el individualismo y la economía de casino: aquella que propicia ganar el mayor dinero posible en el menor tiempo. Ha puesto como único objetivo de la política económica el combate contra la inflación a costa del paro y de la desertización industrial. Ha repetido y practicado las absurdas doctrinas que conducen al debilitamiento del sector público [...] ha abjurado del Estado del bienestar sin haber hecho siquiera un esfuerzo serio por implantarlo [...] se ha defendido con total irresponsabilidad que la mejor polftica industrial es la que no existe $y$ que el mercado es el que tiene que so- 
lucionarlo todo en este campo [...] se ha asumido el discurso antisindical: el de pregonar que las organizaciones de defensa de los trabajadores son un factor no de cohesion y de avance social sino de freno y obstáculo para el crecimiento de la economías. ${ }^{15}$ Lo asombroso y lo tremendo del "éxito" del neoliberalismo es que, además de haber arrinconado la crítica libertaria al Estado del bienestar, ha combatido con tal dureza los fundamentos del consenso de posguerra que los sindicatos han tenido que defender en muchas ocasiones solos y a la desesperada lo que eran principios compartidos por todos en décadas anteriores. Así hoy parece revolucionario defender la estabilidad en el empleo, un sector público fuerte, unos sindicatos enraizados en la sociedad y un papel redistribuidor del Estado. Si somos un poco rigurosos debcmos reconocer que en muchas ocasiones los sindicatos (que en países como España es lo poco que queda de izquierda social) simplemente oponen el "modelo renano" de capitalismo al modelo neoliberal. M. Albert en su obra Capitalismo contra capitalismo ha analizado las diferencias entre ambos modelos: "Según el modelo anglosajón para forzar la máxima competitividad de una empresa hay que forzar la competitividad individual, de cada uno de los emplcados. Por lo tanto, cs necesario, siempre y sin excepciones, reclutar a los mejores, y para evitar perderlos, pagarles en todo momento su valor según el mercado. El salario es entonces esencialmente individual y precario, como el empleo mismo. En la concepción renana, por el contrario, se considera que esta cuestión no es la esencial. La empresa no tiene derecho a tratar a sus empleados como a un simple factor de producción que compra y vende en el mercado como si fuera una materia prima. Tiene, por el con- trario, un cierto deber de seguridad, de fidelidad, de formación profesional que cuesta cara. En consecuencia más que pagar a cada uno su valor instantáneo según el mercado, la empresa debe ocuparse de la formación, limitar las excesivas diferencias salariales, evitar las rivalidades destructivas" ${ }^{16}$ Este modelo de empresa unido al papel del Estado en el marco de una cconomía social de mercado y a la presencia de sindicatos fuertes ha sido el modelo de referencia de los sindicatos frente a la ofensiva neoliberal que todo lo cifraba en la menor reglamentación como condición sine qua non para modernizar la producción y alcanzar una política de crecimiento y empleo. Esa lucha sindical ha sido una lucha a la defensiva porque ala larga noche neoliberaln 17 lo ha invadido todo.

Una resistencia tan solitaria y desesperada algo nos debe hacer pensar acerca del problema que el "éxito" del neoliberalismo comporta para la compatibilidad entre capitalismo y democracia. Decíamos al principio que capitalismo y democracia aparecían como incompatibles a principios de siglo. El final de siglo muestra una fortísima ofensiva en el campo liberal que amenaza con arrumbar elementos decisivos del pacto de posguerra. Si estos componentes del pacto posbelico, hoy ya fiertemente erosionados van siendo demolidos ¿qué puede ocurrir? Cabe pensar en un aumento de la marginación social en la medida en que la "mayoría satisfecha" vaya dejando a un sector de la población cada vez mayor fuera de los circuitos del trabajo. del consumo y de la representación política. Si esto ocurre, y dado que ese fenómeno de la marginación comienza a afectar a muchos miembros de las clases medias y que a su vez se ve incrementado por las oleadas de trabajadores que emigrarán del Sur al Norte, 
la situación puede comenzar a ser preocupante. El porcentaje de trabajadores en paro es muy alto en Europa (no digamos en España), el modelo europeo de sociedad tiene serias dificultades para competir en un mundo donde la economía se ha globalizado, sin creación de riqueza es imposible financlar el bienestar [...] estas y otras muchas afirmaciones son constantes en cualquier medio de comunicación. La cuestión, sin embargo, no es designar el problema sino ofrecer una posible salida y aquí es donde se nota el "éxito" del neoliberalismo y la parálisis de la izquierda. El neoliberalismo se mueve siempre en una lógica doble. Si por socialismo se entiende racionalización de los medios de producción y planificación centralizada, esa respuesta ha sido descartada por sus resultados históricos. Si por el contrario se entiende fuerte imposición fiscal y medidas redistributivas esa política tiene un límite en la medida en que una presión fiscal muy alta provoca la desafección de las clases medias y de la "mayoría satisfecham. ¿Qué hacer entonces?

Mientras la izquierda no logre reinterpretar en una clave propia la experiencia del comunismo se asociará socialismo a dictadura de partido ánico e ineficacia económica. Sólo rescatando una tradición política que ha existido $y$ hoy se quiere desconocer, una tradición de crítica socialista del estalinismo, la izquierda no quedará arrumbada en esa equiparación entre la ex- periencia de los paises del este y el socialismo. En segundo lugar sólo si es capaz de volver a alcanzar mayorías electorales progresistas podrá tener alguna posibilidad de recomponer la situación. Cualquier lector pensará que es obvio que en democracia sin alcanzar la mayorra no se puede gobernar pero he añadido el adjetivo, cquívoco y ambiguo, de "progresista" para mostrar que no me parece nada sencillo combatir a la "mayoría satisfecha" y vincular a un mismo proyecto al trabajador en paro y al trabajador con empleo, al inmigrante y al profesional de clase media, al jubilado y al insumiso; alcanzar esa mayoría exige un debate político-moral muy complcjo. En tercer y último lugar, alcanzada esa mayoría hay que hacer una política distinta a la neoliberal y eso no es posible en un solo pais, dada la mundialización del capital. Ese proyecto exige un nuevo internacionalismo, tan fácil de enunciar como difícil de realizar.

Si no logramos articular una relectura de la propia tradición, una articulación de una mayoría progresista y un proyecto internacional, el séxito" del neoliberalismo será algo más que un fenómeno coyuntural de los años ochenta y marcará el inicio de una nueva época peor que la que produjo el consenso de posguerra. Una época en la que, como a comienzos de siglo, será de nuevo difícil compatibilizar las exigencias del capitalismo y los principios rectores de la vida democrática.

\section{NOTAS}

1. R. Aron, Ensayo sobre las libertades, Madrid, Alianza, 1966, p. 121 .

2. $y$ bid., pp. 121-122.

3. R. Aron, Mentonas, Madrid, Alianza, 1985, p. 584 .

4. R. Aron, Ensayo sobre las libertades, op. cit, P. 133.
5. D.A. Stockman, El trituto de la poltitica, Barcelona, Grijalbo, 1986, p. 18 .

6. Ibid., p. 18.

7. F.A. Hayek, Canino de servidumbre, Madnid, Alianza, 1978, p. 25.

8. H. Young, Margaret Thatcher, Buenos Aires, Javier Vergara, 1989, p. 604. 
9. Ibid., p. 603 .

10. J.K. Galbraith, La cultura de la satisfacción, Barcelona, Ariel, 1992, p. 26.

11. Ibid, p. 29.

12. Ibiat, p. 30 .

13. Tbid, p. 32.

14. N. Redondo, El sindicalismo de clase en al moviniento obrera, Madrid, Escuela Julián Besteiro, 1993, p. 42.

15. $M b i d, 43$.

16. M. Albert, Capitalismo contra capitalisno, Barcelona, Paidós, 1991, p. 110.

17. VV.AA., La larga noche neoliberal, Barcelona, Icaria-Instituto sindical de estudios, 1993.

\title{
«Dígales que mi vida ha sido maravillosa»: ética y existencia en $\mathbf{L}$. Wittgenstein
}

\author{
ANTONI DEFEZ I MARTÍN \\ Universidad de Valencia
}

\begin{abstract}
Mi ideal es una cierta indiferencia: un templo que cierre el paso a las pasiones sin ser afectado por ellas.
\end{abstract}

L. WITTGENSTEIN, Vemntschte Benterkungen

Una de las constantes del pensamiento de Wittgenstein es su concepcion unocientificistan de la actividad filosófica: la filosofía siempre debía quedar al margen de la ciencia natural. $\mathrm{Y}$ ello a pesar de que, en su opinión, el conocimiento científico era la mejor forma de acceder al "cómo" de la realidad. Recordemos que para el Tractatus (TLP) el ámbito del usentido» coincidía con el ámbito del conocimiento científico (p.e., $T L P, 4.11$ y 6.53), mientras que el segundo Wittgenstein reconocerá la superioridad de la ciencia respecto a otras "formas de vida" $\mathbf{u}$ otros "sistemas de creencias», sin ser, no obstante, justificable esta superioridad ni filosófica ni moralmente -digamos, "racionalmente" (vid., p.e., Observaciones sobre La Rama Dorada de Frazer). Ahora bien, y pese a estos meritos, para Wittgenstein, la filosofía no estaba interesada por lo que pudiera establecer la ciencia. Los logros de ésta no podían ser usados para solucionar los problemas de aquélla; y tampoco era tarea de la filosofia ofrecer una reconstrucción o una fundamentación del conocimiento científico. Por el contrario, la actividad filosofica debía reducirse a actividad o análisis dilucidatorio del lenguaje, bien en el sentido de esclarecer sus condiciones trascendentales de posibilidad a partir de la lógica extensional en la epoca del Tractatus, o bien en la más modesta función, ya dentro del pensamiento que se desarrolla en las Investigaciones Filosoficas (IF), de hacer patentes las condiciones que de facto posibilitan y regulan los distintos «juegos lingüísticos». Entendida de esta manera, la filosofía "había de dejar todo como están, ya que a través de su ejercicio, al no lanzar hipótesis y al no utilizar las hipótesis de la ciencia, no consigue ningún conocimiento nuevo que antes no poseyéramos (vid., p.e., IF $\$ 122-128, \S 309$ y $\S 599$ ). En realidad, la única ganancia que con ella alcanzaríamos es la uclaridad conceptual» $y$, en consecuencia, el benefi- 